\title{
Unique Challenges of Decision-Making Process on Crowdfunding Platforms-An Exploratory Study
}

\author{
Yu Lei \\ School of Business \\ SUNY College at Old Westbury \\ leiy@oldwestbury.edu
}

\author{
Ali Alper Yayla \\ School of Management \\ Binghamton University, SUNY \\ ayayla@binghamton.edu
}

\author{
Surinder S. Kahai \\ School of Management \\ Binghamton University, SUNY \\ kahai@ binghamton.edu
}

\begin{abstract}
Crowdfunding gives opportunities to novice entrepreneurs to raise funding for their novel ideas. However, lack of monitoring of projects and funds coupled with the lack of experience of project initiators create high levels of uncertainty for potential funders. In this study, we aim to examine how funders' decision making process is affected by different types of uncertainty related to the project initiators. Unlike traditional e-commerce where consumers buy a finished product, in patronage based crowdfunding platforms, funders invest in and buy a product that is yet to be finished. This creates a unique uncertainty based on project initiators' competence. Our results show that uncertainty based on project initiators' competence and opportunism increase product performance uncertainty. Moreover, the dynamics of project initiator and product uncertainty are affected by the complexity of the product.
\end{abstract}

\section{Introduction}

Sharing economy is a new form of online transaction activity that utilizes the contemporary information technology to promote a more efficient method for allocating surplus resources [17][32]. By providing an opportunity for participants to connect to each other, sharing economy is gradually becoming a unique but less-regulated economic activity due to lack of a rigorous overseeing system compared to more traditional and established ecommerce [25]. The absence of such system creates unique challenges to participants, especially the amount of uncertainty they need to cope with [33].
Crowdfunding is a prime example of sharing economy activity where participants encounter various types of uncertainty [6]. As a new form of fund raising method, crowdfunding has attained widespread popularity and attention in recent years. Crowdfunding aims at distributed audiences over the Internet so that there are higher chances for new entrepreneurs and wide range of products to be funded [26]. However, existing research indicates that investment activities in crowdfunding is mostly based on herding behavior [8][9][18]. One potential explanation of this behavior is the high level of uncertainty since investors have limited information about the project initiators (seller) and their products. More specifically, the product that crowdfunding will afford usually is one of a kind and also yet to be created if it is successfully funded [2]. Due to this nature, funders are facing a higher product uncertainty since there are fewer existing products can be compared to, and almost no previous history of the focal product. Therefore funders have to evaluate the quality of the project initiator and subsequently infer the potential quality of the product yet to be produced. As shown by previous research, product uncertainty is directly affected by seller uncertainty [12], however compared to traditional ecommerce users whose main concern is whether seller is honest and ethical (e.g. seller advertises the authentic product but provides the counterfeit) [15][28], crowdfunding investors are facing a new type of seller uncertainty because not only they need to assess seller's ethical traits, but also seller's capability to produce and deliver the promised product [23].

We postulate that on a crowdfunding platform, when funders are uncertain about products, they infer the product quality via project initiators, they experience both types of seller uncertainty, which are distinct and therefore should be examined separately. 
For example, the project initiator can be faithful and ethical at the beginning of the project, but later due to the limitation of his/her capability, fails to meet the expectation, resulting in lower quality products, delivery delay, or even project cancellation. Parallel to these arguments, in this paper, our goal is to explore this unique feature and discover how this challenge affects decision-making process. Main research questions we aim to answer are:

RQ1: when funders infer a product quality, what types of seller uncertainty are they facing during decision-making process?

RQ2: how the dynamics between different types of seller uncertainty affect funders' perception on product uncertainty?

Based upon agent theory and extant judgement and decision making research, we propose two constructs associated with sharing economy: seller opportunism uncertainty (SOU), which captures ethical characteristics of sellers (e.g. whether seller is honest) and seller-competence-uncertainty (SCU), which captures actual capability of sellers to deliver services/products. As an example, imagine a project initiator proposes a new project. Funders may be uncertain about the quality of the product since the product has not been created yet. They can only infer the performance of the product from the information project initiator provides on the platform. Therefore, funders may concern about the project initiator regarding 1) whether project initiator discloses all information faithfully (SOU), and 2) whether project initiator has the capability to deliver the product (SCU) even though he/she does not intent to deceive funders. By conceptualizing these two uncertainties, we attempt to provide richer understanding of funders' information processing and decision making process, especially how these two different types of seller uncertainty affect the product uncertainty. We argue that SOU are SCU distinct, and each reflects funders' unique perception about seller uncertainty, and therefore both of them should affect the product uncertainty. Furthermore, investors are likely to perceive different levels of SOU and SCU based on product complexity, such that the higher the product complexity the stronger the effect of SOU and SCU on product uncertainty, and the changes in SCU should be more evident than SOU.

Overall we aim to make two main contributions and extend the existing research: first, we identify the types of uncertainty that funders need to cope with in the crowdfunding environment. Compared to treating seller uncertainty as a single construct, our research shows that seller's competence uncertainty is independent of seller's opportunism uncertainty. Second, we investigate the dynamics between SOU and SCU with respect to product complexity. This is an important aspect of the dynamics because our results reveal that the impact of SOU and SCU varies according to the level of product complexity. It should be noted that, there are different forms of sharing economy activity such as ride sharing, accommodation based, crowdfunding, and each form possesses its own unique characteristics. The research context of the current study is set in crowdfunding environment, which is one of the most popular sharing economy activities. We believe this context can exemplify the difference between SOU and SCU, and best serve our research purpose to explore various dimensions of seller uncertainty, and the dynamics between seller uncertainty and product uncertainty while the product complexity varies.

\section{Literature Review \& Hypothesis Development}

Previous research has shown that seller uncertainty can significantly impact users' perception of e-commerce vendors and the products they sell [12][30]. Vendors with established reputation are more successful in relieving buyers' fear about seller opportunism [30], and consequently buyers are more likely to accept and purchase from these reputable sellers [15]. In other words, buyers perceive these sellers to be trustworthy, and this sense of trust between sellers and buyers has been proved to be very important in the decision-making process [4][12]. However, establishing trust between sellers and buyers may require significant amount of time through repeated transactions [13]. It is probably even harder to achieve in the crowdfunding context because many project initiators are novice entrepreneurs and may not have prior successful experiences 0 . Thus, the principal-agent problem manifests in such environment [5][24].

In e-commerce, buyers (principal) concern that sellers (agent) may hide necessary information before the transaction, or may not act ethically after payment is received [30]. The main obstacle for buyers to purchase confidently is assessing the uncertainty. Here, we focus on two major types of uncertainty experienced by the buyers, seller uncertainty and product uncertainty [12]. 


\subsection{Seller Uncertainty}

The seller uncertainty construct is particularly critical in the judgement and decision making discipline [3] [31]. Our understanding of seller uncertainty has evolved during past decades. The advancement of information technology, the emergence of the Internet and new purchasing behaviors create unique challenges. In the past, consumers encounter seller uncertainty in a face-toface environment, and they may infer seller's quality more directly. However consumers right now need to cope with such uncertainty in a much more complex environment, where purchase can be completed via both physical and virtual media. In this context, consumers may not be able to evaluate sellers' traits comprehensively, and information asymmetry issue is even more challenging to uncover [27].

In the current study, seller uncertainty is conceptualized as opportunism uncertainty and competence uncertainty. The former captures the perceived opportunism of the project initiator as a result of lack of any monitoring mechanisms once the project is fully funded, whereas the latter captures the perceived capability of a project initiator to deliver a high performing product. While seller's opportunism uncertainty has been studied extensively in previous research [29][30], seller's competence uncertainty has not been scrutinized closely. Although the competence issue is prominent in many sharing/access economy activities [14][23], consumers may not conceive this uncertainty completely.

As identified by existing research, in e-business, seller uncertainty is caused by buyers' incapability to evaluate sellers due to the ex ante sellers' misrepresentation of products and ex post seller's opportunism [12][30]. In other words, buyer will perceive high seller uncertainty when sellers do not fully disclose their characteristics (ex ante) and do not cooperate afterwards (ex post) [12]. As we can see, these two potential problems that lead to seller uncertainty are both related to sellers' honesty. In crowdfunding environment, seller uncertainty also exists and greatly obscures projects' quality and success. However, it is displayed differently in patronage type of crowdfunding (e.g. Kickstarter) from traditional online market. First, project initiators do not primarily aim and "sell" the products for profits, rather, project initiators are willing to offer those products at a lower price compared to the future retail price [20]. Second, project initiators may not have intention to purposely conceal any products' features ex ante, because (1) all products are new and therefore have chances of defects and (2) most products are advertised even before the prototypes are created, and are due in the future, thus even sellers themselves cannot successfully evaluate products. However, even though sellers in crowdfunding contexts may not have the motivation to hide important information, the potential ex ante peril still exists since sellers may be too optimistic about their capabilities and products' performance. Therefore, this uncertainty is not due to seller's dishonesty but rather it is due to seller's competence. This unique uncertainty is in addition to seller's opportunism uncertainty, which exists in traditional online markets [16], since project initiators may be shirking after their projects are fully funded, which results in low quality end products.

To summarize, in crowdfunding context, seller uncertainty has two distinct dimensions. On the one hand, funders are concerned about whether sellers are competent enough to finish the product on time. On the other hand, funders fear that project initiators are not motivated to deliver high quality products. Based on these distinct features, we define seller uncertainty in the crowdfunding contexts as seller's opportunism (ex ante) and seller's competence (ex post).

Previous research, especially e-business research, has mainly focused on seller uncertainty, whereas product uncertainty has not been studied extensively [12]. Limited number of existing studies reported the positive effect of seller uncertainty on product uncertainty [12]. Two types of product uncertainty have drawn attention from scholars: performance uncertainty and product fit [19]. Performance uncertainty captures how well the finished product will perform as described initially. Product fit captures the match between product attributes and the expectations of the buyer and whether the buyer will have a positive experience with the product after the purchase. These two aspects of product uncertainty are considered distinct [19]. In this study, we examine product performance uncertainty which is closely related to seller uncertainty. Following the literature, we posit the positive effect of seller uncertainty on product uncertainty. That is;

Hla: Other things being equal, sellercompetence-uncertainty will increase product performance uncertainty. 
H1b: Other things being equal, selleropportunism-uncertainty will increase product performance uncertainty.

\subsection{The Moderating Role of Product Complexity}

Previous research has shown that when product complexity increases, consumers perceive higher levels of uncertainty [21]. In the current study, we postulate that when making decisions in a crowdfunding environment, funders usually face both types of seller uncertainties simultaneously, and they interact and exert influence during the decisionmaking process. Thus, investigating the dynamics of SOU and SCU with regards to complexity can provide a more complete understanding of the effect of seller uncertainty on product uncertainty.

Existing research reports that when people believe they can control their decision making process, they overestimate their decision performance. This phenomenon is denoted as "illusion of control" [11][22]. In the crowdfunding context, when product complexity is low, funders may have the "illusion of control" because the skills/capability needed to accomplish such project is not as challenging for the seller. As a result, funders may perceive low seller competence uncertainty. Yet, seller opportunism uncertainty may still play an important role when product complexity is low since it is related to the seller's ethical nature, not to the product's features, although the level of such uncertainty may be lower compared to the high complexity situation. In other words, the "illusion of control" occurs when funders either have a good understanding of the product or the product itself is relatively easy to manufacture. In either case, due to illusion of control, funders' main concern on sellers' capability may not be as salient as the concern on sellers' opportunistic behaviors to deliver low quality products.

For instance, if the crowdfunding project is a photo album by a photographer, the perceived product complexity would be low and the quality of the photo album is more likely to be dependent on the photographer's intentions (e.g., will she finish the photo album) rather her capabilities (e.g., can she take the photos and make a book out of them). On the other hand, the concern about seller's competence arises when the product complexity is high. In these situation, funders' lack of knowledge about the product raises concern regarding the sellers' capability of delivering the products as promised.

We argue that there is a distinction between the sources of these two types of uncertainties. In seller opportunism uncertainty, decision maker's main concern is the uncertainty as a result of seller's opportunism; whereas in seller competence uncertainty, the decision maker focuses on the attributes and specification of products. In other words, under different levels of project complexity and innovativeness, the nature of concerns on sellers' uncertainty is different. One should notice that the distinctive features of SOU and SCU does not suggest that individuals experience only one type of uncertainty, instead, they concern both seller's opportunism and seller's competence, and their magnitude varies under different levels of project complexity. Parallel to these discussions, we hypothesize that:

H2a: Other things being equal, in high product complexity, SCU will have a more positive effect than SOU on product performance uncertainty.

H2b: Other things being equal, in low product complexity, SOU will have a more positive effect than $S C U$ on product performance uncertainty.

\section{Methods}

The survey questions used in the study are all validated by the previous research. Each construct is briefly described as follow.

Seller Uncertainty Based on the conceptualization, seller uncertainty construct has two dimensions: seller competence uncertainty and seller opportunism uncertainty. Seller competence uncertainty items are adapted from previous research [15][30], which mainly focus on funder's perceived uncertainty towards seller's capability to deliver a satisfied product. Seller opportunism uncertainty items measure the perceived uncertainty of whether sellers can faithfully finish the projects with high quality. These questions are also adapted from existing studies [12][30].

Product Uncertainty: Product uncertainty is measured as the perceived uncertainty about future quality or performance of the product. It captures perceptions of funders of the quality and performance of the product with respect to project description [30].

Project Complexity: Consistent with previous research on task complexity [21], we first select different types of projects including both experience 
goods and search goods. Projects that may need certain level of expertise to accurately assess product features, such as a 3D printing device, are deemed as a high complexity project. On the other hand, projects that may be evaluated with less professional knowledge, such as creating a photo album, are considered as a low complexity project. The perceived project complexity is measured by a 7point Likert scale. If the mean is less than 3.5, the project is considered low complexity, if the mean is more than 3.5, the project is considered high complexity. Furthermore, in order to find the products which correctly represent complexity level, we conducted a pilot study to screen the most appropriate products. In the pilot study, six different products (three high complexity; three low complexity) were shown to and evaluated by subject. The product rated with the highest complexity level is chosen as the high complexity project ( $3 D$ printer), and similarly product rated with the lowest complexity level is used as the low complexity project (photo album).

The data for the current study is obtained through Amazon Mechanical Turk (MT). Compared to traditional student samples used in decision making research, subjects recruited via MT are more demographically representative, and therefore ensure the generalizability of the findings. Previous research also found that common issues in experiment design such as internal (e.g. subjects' attentiveness) and external validity (e.g. results persistency in other experiment settings) do not constitute problems in data collected from MT subjects [7]. Because crowdfunding is not legal in all countries, we limit MT subjects to the United States and Canada. Moreover, to ensure high quality response from MT, we required that subjects must have high acceptance rate (> 95\%) from previous tasks on MT, and also added random attention check questions.

In sum, 326 subjects are recruited from MT. Among them, 19 failed the attention check which results in a final 307 valid answers, and for each valid answer, a participant were paid $\$ 0.70$ as a reward. Among all of the 307 subjects, 163 (53.1\%) were male, $144(46.9 \%)$ were female. The average age of the subjects is in the 45-50 range. In general, subjects are satisfied with social media platforms (e.g. Facebook) (mean: 5.21/7) and online transactions (e.g. online payment, e-commerce) (mean: 5.92/7), and most of them are relatively familiar with crowdfunding platform such as Kickstarter (mean: 4.74/7). Moreover, perceived project complexity is tested again to confirm the results of the pilot study. The results of the t-test show that there is a significant difference $(p<.001)$ between perceived complexity of a photo album project (mean: 2.98/7) (low complexity) and a 3D printer project (mean: 5.43/7) (high complexity).

\section{Results}

We used path model analysis to test the hypotheses of the current study. Our analysis shows that under both scenarios (low vs. high), seller competence uncertainty and seller opportunism uncertainty have significant positive effect on product performance uncertainty. For the low complexity project, seller competence uncertainty is positively correlated with product performance uncertainty $(\beta=0.31, p<.01)$, and seller opportunism uncertainty is positively correlated with product performance uncertainty $(\beta=0.50, p<.01)$. For the high complexity project, seller competence uncertainty is positively correlated with product performance uncertainty $(\beta=0.20, p<.01)$, and seller opportunism uncertainty is positively correlated with product performance uncertainty $(\beta=0.63, p$ $<.01)$. These results support H1a and H1b.

To test the moderating effect of product complexity ( $\mathrm{H} 2 \mathrm{a} \& \mathrm{H} 2 \mathrm{~b}$ ), we compare the paths coefficients within each scenario (low or high). Within scenario comparison shows that in the low complexity scenario, the path coefficient of seller competence uncertainty to product uncertainty $(\beta=$ $0.31, \mathrm{p}<.01)$ is smaller than the path coefficient of seller opportunism uncertainty to product uncertainty $(\beta=0.50, p<.01)$. This result indicates that subjects perceive stronger seller opportunism uncertainty than seller competence uncertainty when evaluating low complexity product, therefore supporting H2a. However, contrary to our expectations, in high complexity scenario subjects also perceive stronger seller opportunism uncertainty $(\beta=0.63, \mathrm{p}<.01)$ than seller competence uncertainty $\beta=0.20, \mathrm{p}<.01$ ). Thus $\mathrm{H} 2 \mathrm{~b}$ is not supported. Compared to low complexity scenario, it seems that seller opportunism uncertainty is even stronger in high complexity scenario, and furthermore the seller competence uncertainty decreases. This result may due to a halo effect, under which if people consider a project is complicated, their concern can spill over to sellers' ethics. We further investigated this unexpected result 
in our post-hoc analysis. These results are shown in Table 1.

\begin{tabular}{|c|c|c|}
\hline & \multicolumn{2}{|c|}{ Product Complexity } \\
\hline Path & Low & High \\
\hline SCU $\rightarrow$ PU & 0.31 & 0.20 \\
\hline SOU $\rightarrow$ PU & 0.50 & 0.63 \\
\hline
\end{tabular}

\section{Table 1. Path coefficients}

\subsection{Post-hoc analysis}

To further understand the dynamics between seller opportunism uncertainty and seller competence uncertainty under different levels of project complexity, we compare the coefficients of the same path across different scenarios (between low \& high) using group analysis.

The group analysis is conducted using a permutation method developed by [10]. Based on path coefficients and standard errors, $t$ value is obtained by using the following formula:

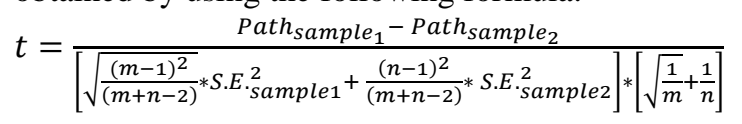

Utilizing this method, we find that there is a significant difference $(p<.05)$ between the path coefficients of seller opportunism uncertainty to product uncertainty (i.e. the increase from 0.50 to 0.63 is significant), and a marginally significant difference $(p<.1)$ (i.e. the decrease from 0.31 to 0.20$)$ is found between path coefficients of seller competence uncertainty to product uncertainty. The results seem to imply that funders' concern on project initiators' opportunism behaviors increases while the project complexity becomes high, and it is even becoming funders' major concern and may start to ignore whether project initiators have the capability to deliver the products.

As discussed, contrary to expectations, our result shows that seller competence uncertainty has a smaller effect for inferring product quality when project complexity increases. One factor that may lead to this phenomenon is funders' familiarity with the product. For example, when people have the knowledge of a certain product, they may understand the required level of expertise to build an excellent product. On the other hand, when people are unfamiliar with the product, they may not have the ability to assess project initiators' capability, rather they may forego their concern on sellers' competence and focus on sellers' opportunism behaviors, which they can try to infer based on the information provided. In order to verify our speculation, we conduct the within scenario $t$-test to compare the level of perceived seller competence uncertainty. For the high complexity project, people who are more familiar with the product indeed perceive more seller competence uncertainty compared to people who are unfamiliar with a $3 \mathrm{D}$ printer ( $\mu=4.32$ vs. $\mu=3.88, p$ <.05). In other words, they are more aware of the existence of sellers' competence uncertainty. This speculation is also confirmed in low complexity scenario. For the Photo Album project, funders who claim to be more familiar with the project has a higher concern on sellers' competence $(\mu=3.56)$ compared to funders who are less familiar with the project $(\mu=3.14)$, and a significant difference is also observed $(p<.05)$.

\section{Discussion}

This study aims to examine how funders' decision making process is affected due to perception of different types of seller uncertainties. Specifically, we investigate the effects of seller opportunism and seller competence uncertainty on product uncertainty, as well as the dynamics between these two types seller of uncertainty under different levels of product complexity. We find that funders experience two distinct types of seller uncertainty, and their effect on product uncertainty varies by project complexity. Some of the key findings of the study are as follows. First, under either high or low project complexity, funders concern more about sellers' opportunistic behaviors, and less about sellers' capability to deliver a good quality product. Furthermore, when project complexity increases, the effect of seller's opportunism uncertainty on funders' evaluation of potential products is significantly higher, compared to the same effect when complexity level is low. These results seem to imply that when the project becomes complex, funders do not evaluate the quality of potential products based upon project initiators' capability, rather funders will "by default" acknowledge and believe that project initiators have the expertise to accomplish the projects. This is especially the case for funders who are not familiar with the product. According to funders' perceptions, whether the delivered products will possess good quality mainly depends on project initiators' good faith.

Our findings have several implications. Compared to previous research which mainly focuses on seller's ethical characteristics [12][30], this study proposes 
that seller competence uncertainty may independently exert influence on perceived product uncertainty. Moreover, although different types of seller uncertainty have been investigated in the literature, these studies are mostly in the context of e-business or at least for finished products, whereas in a crowdfunding context, it is important to investigate funders' uncertainty regarding sellers' competence of delivering satisfactory products, because the decision maker is not only a buyer but also an investor of a product which is yet to be manufactured. Therefore, in addition to sellers' ethnical characteristics, the product performance uncertainty experienced by funders can also be affected by sellers' competence. Furthermore, the magnitude of seller uncertainty perceived by people are significantly different. Especially for high complexity products, people have a stronger concern about seller's opportunistic behaviors, whereas they have less concern about seller' competence. The further investigation of our unexpected result revealed that seller competence uncertainty is partly determined by funders' familiarity of the product. Those who have familiarity with the product have more concerns of seller competence both in high and low product complexity, highlighting the complexity of understanding decision-making process.

This research also has practical implications. As discussed in the beginning, the urgent issue faced by all crowdfunding platforms is that there might be too many "disqualified" projects, where funders do not have access to all information, especially the crowdfunding website 1) does not have a supervisory system to monitor the quality of the finished product; and 2) provides low barriers to entry. Combined with these issues, people already started to have negative impacts on crowdfunding due to their unsatisfactory decisions on failed projects. The negative attitude towards crowdfunding could further hurt the platform since crowdfunding websites could make a profit only when projects are successfully funded. The findings of our current research may guide future features of crowdfunding platforms. One the one hand, crowdfunding websites should enforce administrative mechanism to supervise and inspect to filter out disqualified projects, on the other hand, crowdfunding platforms could integrate social networking sites into current functions in order to assist funders with their decision making. For examples, if funders are able to obtain opinions from other fellow funders, or share their investing activities with friends to receive comments on the crowdfunding platform, funders may retrieve extra information to help them formulate decision. As people become more satisfied with their choices, they would reinvest on the platform, which also benefits the platform. Given that most of popular projects on the crowdfunding platforms are high-tech products, which accompanied by high complexity, crowdfunding platforms may disclose more information about project initiators and their credentials.

Although the research tries to account for extensive aspects of study design and conceptualization, it also has limitation. One limitation is due to subjects' geographic characteristics. The sample of this study is mainly from North America, therefore there might be a cultural bias. It is widely known that uncertainty avoidance and the development of trust is closely related to national culture [13]. Since the current study is conducted predominantly in one type of culture, it would be constructive to test the same model in different countries, or under another cultural background. In the future research, we would like to examine the influence of such variables, which may include culture, gender and age, on the perception of different types of seller uncertainties, especially when these variables interact with the project complexity.

\section{Conclusion}

We now live in an era that everyone is connected by Internet, where social media plays an important role in our daily life. On the one hand, people are enjoying the convenience of abundant information existing on the Internet, and on the other hand, people are burdening with the possibility of information overload which causes difficulty in making decisions. How to effectively using and evaluating the information is becoming a major concern today compared to difficulties of lack of information experienced in the past. In a crowdfunding environment, people have to decide between many similar products in a situation where most of the time they are not familiar with the project initiators or their innovative products. Therefore, they have to depend on certain benchmarks to confirm or validate their decisions. Current research provides new insights on funders' decision making mechanism, and how crowdfunding platforms can help funders to reduce their concern. 
As a consequence of rapid development of Internet and innovative use of such technology, people are constantly facing new challenge when making decisions. It is important to accurately identify what our question is and why we have such concerns. By examining the influence of different types of seller uncertainty, we can establish a more comprehensive understanding of who will be offering the products/services, and how they will manufacture and deliver their products/services, which may help us evaluate such products/services better.

\section{References}

[1] Agrawal, A., Catalini, C., and Goldfarb, A. 2011. Offline Relationships, Distance, and the Internet: The Geography of Crowdfunding. National Bureau of Economic Research, Cambridge, MA.

[2] G.K. Ahlers, D. Cumming, C. Günther, and D. Schweizer, "Signaling in Equity Crowdfunding", Entrepreneurship Theory and Practice, 39(4), 2015, pp. 955-980.

[3] G.A. Akerlof, "The Market For "Lemons": Quality Uncertainty and the Market Mechanism", The Quarterly Journal of Economics 84(3), 1970, pp.488500 .

[4] S. Ba, and P.A. Pavlou, "Evidence of the Effect of Trust Building Technology in Electronic Markets: Price Premiums and Buyer Behavior", MIS Quarterly (26)3, 2002, pp. 243-268.

[5] L.A. Bebchuk, and J.M. Fried, Pay without Performance: The Unfulfilled Promise of Executive Compensation, MA: Harvard Uni. Press, Cambridge, 2006.

[6] P. Belleflamme, T. Lambert, and A. Schwienbacher, "Crowdfunding: An Industrial Organization Perspective", Working Paper, Universite Catholique de Louvain, 2010.

[7] A.J. Berinsky, G.A. Huber, and G.S. Lenz, "Evaluating Online Labor Markets for Experimental Research: Amazon.com's Mechanical Turk", Political Analysis 20(3), 2012, pp. 351-368.

[8] E. Berkovich, "Search and Herding Effects in Peer-toPeer Lending: Evidence from Prosper.com", Annals of Finance (7)3, 2011, pp. 389 -405.

[9] U. Bretschneider, K. Knaub, and E. Wieck, "Motivations for Crowdfunding: What Drives the Crowd to Invest in Start-Ups?", in Proceedings of the 22nd European Conference on Information Systems, Tel Aviv, Israel, 2014.
[10] W.W. Chin, W.W and J. Dibbern, "An Introduction to a Permutation Based Procedure for Multi-Group PLS Analysis", Handbook of Partial Least Squares. Springer, 2010, pp. 171-193.

[11] F.D. Davis, and J.E. Kottemann, "User perceptions of decision support effectiveness: Two production planning experiments", Decision Sciences 25(1), 1994, pp.57-76.

[12] A. Dimoka, Y. Hong, and P.A. Pavlou, "On Product Uncertainty in Online Markets: Theory and Evidence", MIS Quarterly (36) 2, 2012, pp. 395-426.

[13] P.M. Doney, and J.P. Cannon, "Trust in Buyer-Seller Relationships", Journal of Marketing 61(2), 1997, pp.35-51.

[14] Q. Du, W. Fan, Z. Qiao, G. Wang, X. Zhang, and M. Zhou, "Money Talks: A Predictive Model on Crowdfunding Success Using Project Description", In Proceedings of the 35th Americas Conference on Information Systems. 2015.

[15] D. Gefen, E. Karahanna, and D.W. Straub, "Trust and TAM in online Shopping: An Integrated Model”, MIS Quarterly (27)1, 2003, pp. 51-90.

[16] G. Giudici, M. Guerini, and C. Rossi-Lamastra, "Reward-Based Crowdfunding of Entrepreneurial Projects: The Effect of Local Altruism and Localized Social Capital on Proponents' Success", Small Business Economics, 2017, pp.1-18.

[17] J. Hamari, M. Sjöklint, and A. Ukkonen, "The Sharing Economy: Why People Participate in Collaborative Consumption", Journal of the Association for Information Science and Technology (67)9, 2016, pp. 2047-2059.

[18] M. Herzenstein, U.M. Dholakia, and R. L. Andrews, "Strategic Herding Behavior in Peer-to-Peer Loan Auctions", Journal of Interactive Marketing (25)1, 2011, pp. 27-36.

[19] Y. Hong, and P.A. Pavlou, "Product Fit Uncertainty in Online Markets: Nature, Effects, and Antecedents", Information Systems Research 25(2), 2014, pp. 328-344.

[20] M. Hu, X. Li, and M. Shi, "Product and Pricing Decisions in crowdfunding", Marketing Science 34(3), 2015, pp. 331-345.

[21] Z. Jiang, and I. Benbasat, "The Effects of Presentation Formats and Task Complexity on Online Consumers' 
Product Understanding”, MIS Quarterly (31)3, 2007, pp. 475-500.

[22] J.E. Kottemann, F.D. Davis, and W.E. Remus, "Computer-Assisted Decision Making: Performance, Beliefs, and the Illusion of Control", Organizational Behavior and Human Decision Processes, 57(1), 1994, pp.26-37.

[23] Y. Lei, A. A. Yayla, and S. Kahai, "Guiding the Herd: The Effect of Reference Groups in Crowdfunding Decision Making”, In Proceedings of the 50th Hawaii International Conference on System Sciences. 2017.

[24] A. Ley, and S. Weaven, "Exploring Agency Dynamics of Crowdfunding in Start-Up Capital Financing", Academy of Entrepreneurship Journal 17(1), 2011, pp. 85-110.

[25] A. Malhotra, and V.A. Marshall, "The Dark Side of the Sharing Economy... And How to Lighten it", Communications of the ACM (57)11, 2014, pp. 24-27.

[26] E. Mollick, "The Dynamics of Crowdfunding: An Exploratory Study", Journal of Business Venturing (29)1, 2014, pp. 1-16.

[27] J.E. Oxley, and B. Yeung, B, "E-Commerce Readiness: Institutional Environment and International Competitiveness", Journal of International Business Studies 32(4), 2001, pp. 705-723.

[28] P.A. Pavlou, "Consumer Acceptance of Electronic Commerce: Integrating Trust and Risk with the Technology Acceptance Model", International Journal of Electronic Commerce 7(3), 2004, pp. 101-34.

[29] P.A. Pavlou, and A. Dimoka, "The Nature and Role of Feedback Text Comments in Online Marketplaces: Implications for Trust Building, Price Premiums, And Seller Differentiation", Information Systems Research 17(4), 2006, pp. 392-414.

[30] P.A. Pavlou, H. Liang, and Y. Xue, "Understanding and Mitigating Uncertainty in Online Exchange Relationships: A Principal-Agent Perspective", MIS Quarterly (31)1, 2007, pp. 105-136.

[31] M. Spence, "Informational Aspects of Market Structure: An Introduction”, The Quarterly Journal of Economics 90(4), 1976, pp. 591-597.

[32] A. Sundararajan, "Review - 'The Sharing Economy", Financial Times, 2016.

[33] G. Zervas, D. Proserpio, and J.W. Byers, "The Rise of the Sharing Economy: Estimating the Impact of
Airbnb on the Hotel Industry", Journal of Marketing Research 2017. 